Article

\title{
Investigating the Sanding Process of Medium-Density Fiberboard and Korean Pine for Material Removal and Surface Creation
}

\author{
Jian Zhang ${ }^{1,2}$, Junhua Ying ${ }^{1,2}$, Feng Cheng ${ }^{1,2}$, Hongguang Liu ${ }^{1,2}$, Bin Luo ${ }^{1,2, *}$ and Li Li ${ }^{1,2}$ \\ 1 College of Materials Science and Technology, Beijing Forestry University, Beijing 100083, China; \\ wujijianshuai2016@bjfu.edu.cn (J.Z.); yingjunhua66@163.com (J.Y.); chengfeng@bjfu.edu.cn (F.C.); \\ bjfuliuhg@bjfu.edu.cn (H.L.); depwoodlili@bjfu.edu.cn (L.L.) \\ 2 MOE Key Laboratory of Wooden Materials Science and Application, College of Materials Science and \\ Technology, Beijing Forestry University, Beijing 100083, China \\ * Correspondence: luobincl@bjfu.edu.cn
}

Received: 10 September 2018; Accepted: 21 November 2018; Published: 22 November 2018

\begin{abstract}
As an important fine machining method, sanding operation is widely used in most engineered materials. In wood sanding, high material removal rate and surface quality are expected. Clarifying the material deformation in the sanding process is the key to improving sanding efficiency. In this study, a single grit scratching method is used to investigate the material removal and surface creation of medium-density fiberboard (MDF) and Korean Pine (Pinus koraiensis Sieb.et Zucc). It is found that there are some differences in the material deformation during scratching Korean Pine and MDF, compared with grinding metals. A mechanism based on the anatomical cavities absorbing effect was proposed to account for the differences. This mechanism helps to explain why tiny, or even no, "pile-up" (like swelling ridges created by the ploughing effect) occurs during scratching Korean Pine, especially in longitudinal direction. MDF as a densified wood composite presented more pile-up and the variation of pile-up ratio was investigated. The porosity and wood grain direction exert great influence on material removal and surface creation in wood sanding. At the rubbing stage, a new method was developed to confirm the elastic spring back effect both in MDF and Korean Pine scratching. The results obtained and the approaches used in this paper could provide insights into the material removal and surface creation research of other wood species and wood composites to finally improve sanding efficiency and surface quality.
\end{abstract}

Keywords: wood sanding; material deformation; surface morphology; ploughing; elastic spring back

\section{Introduction}

Wood materials are widely used in floor and furniture manufacturing. As an important fine machining method, sanding of wood is usually the last operation of surface modification before gluing and painting, which aims to improve surface quality and ensure dimensional accuracy [1-3]. Looking through related literatures, there are not many systematic studies on material removal and surface creation in wood sanding operation. Stewart studied some surfacing defects and problems related to wood moisture content [4]. He proposed that the defects commonly associated with sanding operations are fuzzy or raised grain, crushed or burned surface, and moisture content exerts great influence on it. Grain raising like lifting of fibres in wood was deeply researched by Evans et al. [5]. They clarified the relationship between wood density and grain raising. In addition, Koehler observed that sanded wood surface was more susceptible to grain raising than planed wood surfaces [6].

Despite the studies on sanded surface morphology and defects, the relationship between the key variables (grit size, cutting depth, feed rate, sanding speed, and grain direction) and material 
removal rate and resultant surface roughness was investigated in abrasive belt sanding operations [7-9]. Sulaiman et al. studied the effect of sanding on surface roughness of rubberwood [3]. It was found that lower sanding grit size gave rougher surface and rougher surface was more wettable compared to smoother surface. The contact angle on the tangential surface was higher compared to radial surface. In Cool and Hernandez's research, the sanding of black spruce wood prior to coating application was optimized for feed speed and grit size [10]. It was found that coarser grit size and higher feed speeds contributed to increased surface roughness and improved wetting properties. However, Sun and $\mathrm{Li}$ observed that the glue bonding strength was not necessarily increased as the surface became smoother for solid wood [11].

For a long period of time, the classical grinding theory of metal is taken as a reference in wood sanding. Considering the grit-workpiece interaction, Hahn divided the material deformation into three phases which are rubbing, ploughing and cutting [12]. Rubbing occurs at the initial engagement of grit into workpiece, with only elastic and slightly plastic deformation of workpiece material. When the grit penetrates deeper into the workpiece, ploughing takes place and clearly visible groove traces with lateral bulging are formed. With the increasing cutting depth, the shearing stress at the ploughed material ahead of the grit increases and a chip is formed, which is called cutting. Analogously, Klocke presented a model of chip formation which consists of three phases [13]. In the first phase, elastic deformation takes place. As the grit penetrates deeper, plastic deformation occurs as well as elastic deformation. When the cutting depth reaches a critical value, the chip removal begins in the third phase, where elastic-plastic deformation and material removal occur superimposed.

For metal, alloy and ceramics, the grinding researches are mainly about material removal and surface integrity from a microcosmic view. Chen and Öpöz presented an investigation of grinding material removal mechanism using finite element (FE) method [14]. In this research, material removal mechanism of grinding, namely rubbing, ploughing and cutting, was discussed with the variation friction coefficient. Anderson et al. compared the spherical and conical single grit on 4340 steel workpieces cutting tests [15]. Meanwhile, a three-dimensional finite element (FE) model was created. It was pointed out that grit cutting edge shape influenced the ploughing and cutting actions significantly $[16,17]$.

The structure of metals is typically considered homogeneous, with the polycrystalline grains equally distributed throughout the material [18]. However, wood materials are composed of cellular structures with other properties such as anisotropy, high porosity and inhomogeneity [19]. Therefore, wood materials vary a lot in material removal and surface creation compared with metals grinding. In this study, the primary aim is to specify both the material elastic and plastic deformation, and to clarify how the deformed material influences the surface morphology. The anatomical cavities absorbing effect was proposed in terms of scratching MDF and Korean Pine. And that will make it possible to explain the differences of material plastic deformation. Grit geometry and multi-grit interference will be further investigated using some other wood species. The ultimate goal is to obtain a complete understanding of the material removal and surface creation of wood materials in the sanding process, which can help develop better sanding technology to improve sanding efficiency and surface quality.

\section{Materials and Methods}

\subsection{Experimental Setup}

Figure 1 shows the single grit scratching test system, which was designed and manufactured to meet the needs of making successive scratches on the surface of the workpiece. The wheel was driven by a precise electrical spindle. The cutting forces were recorded by a 3-axis piezoelectric force sensor (KISTLER 3257A; Kistler Instrumente AG, Winterthur, Switzerland), and the other devices included a charge amplifier (KISTLER 5806; Kistler Instrumente AG, Winterthur, Switzerland) and a signal 
analyzer (NEC OMNIACE II RA2300; NEC Corporation, Tokyo, Japan), the detailed information on the experimental parameters and conditions is described in Table 1.

The workbench has a horizontal movement in $X$ and $Y$ directions and a vertical movement in $Z$ direction. The workpiece and the force sensor were mounted on the workbench through a work fixture. In order to generate successive scratches with different grit cutting depths, a traverse scratching method was used in the study. At the end of workpiece, there was a height less than $1 \mathrm{~mm}$ between the upper surface of workbench and the lower surface of workpiece. And the angle of these two surfaces was less than $0.5^{\circ}$. Hence, the successive scratches were generated with increasing cutting depth when the workbench was in movement of $Y$ direction.

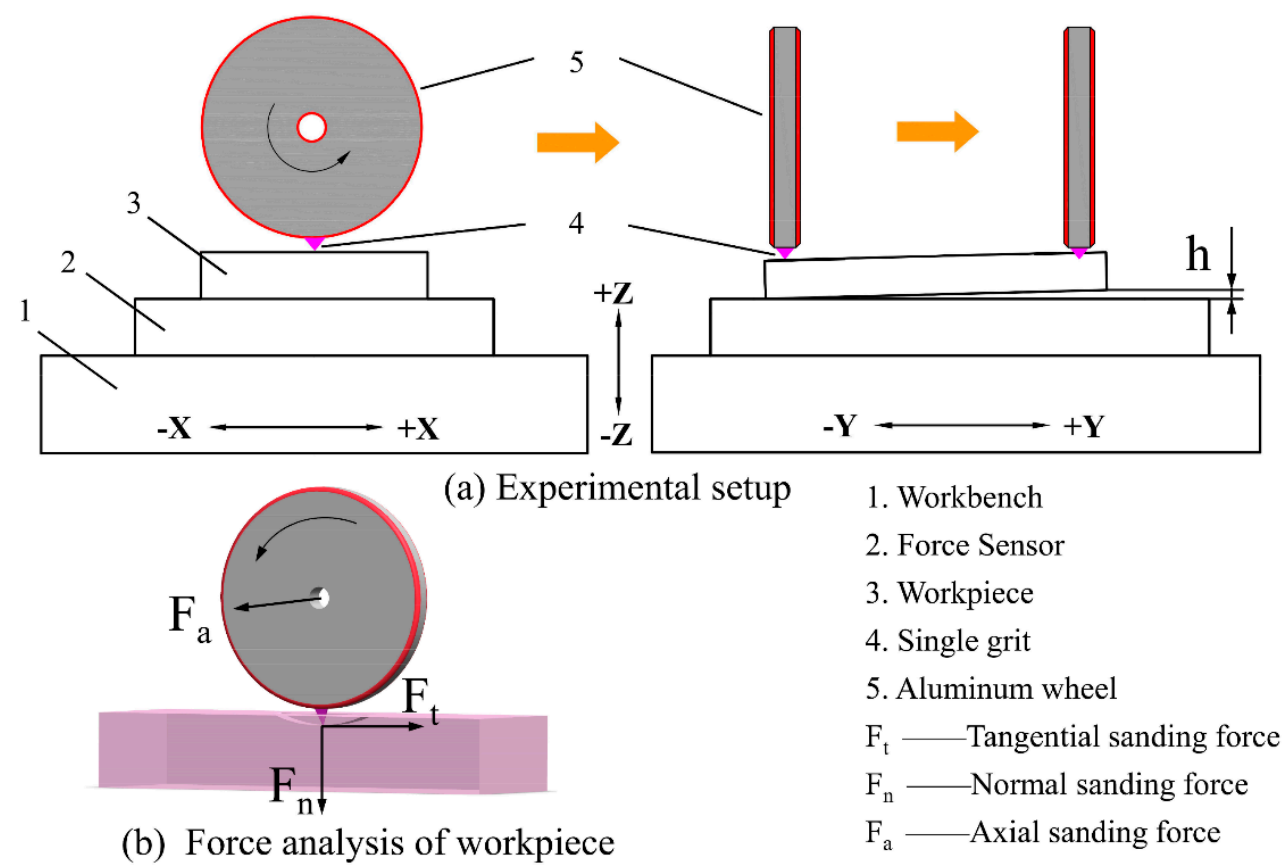

Figure 1. Schematic of the single grit scratching test system: (a) Experimental setup; (b) Force analysis of workpiece.

Table 1. Experimental parameters and conditions.

\begin{tabular}{cc}
\hline Item & Description \\
\hline Feed velocity & $v_{\mathrm{w}}=9 \mathrm{~m} / \mathrm{min}$ \\
Cutting depth & $0-0.5 \mathrm{~mm}$ \\
Electrical spindle & The power is $1.5 \mathrm{~kW}$, the speed is $2100 \mathrm{r} / \mathrm{min}$, with $0.01 \mathrm{~mm}$ accuracy \\
Grinding wheel & Made of aluminum, $0.2 \mathrm{~kg}$ in weight, the diameter is $100 \mathrm{~mm}$, with 0.012 coaxial accuracy \\
3D force sensor & Sensitivity: $F_{X} \approx 7.5 \mathrm{pC} / \mathrm{N}, F_{Y} \approx-7.5 \mathrm{pC} / \mathrm{N}, F_{Z} \approx-3.7 \mathrm{pC} / \mathrm{N}$ \\
Charge amplifier & Measuring range is from $\pm 100 \mathrm{pC}$ to $\pm 1,000,000 \mathrm{pC}$ \\
\hline
\end{tabular}

\subsection{Single Grit and Workpiece Preparation}

The shape of actual corundum grit used in abrasive belt manufacturing is mostly three-pyramid or four-pyramid [20,21]. In this study, a three-pyramid grit was selected, as shown in Figure 2, to create scratches on workpiece surfaces. The detailed information of that grit is listed in Table 2. The grit was strongly glued onto the circumferential surface of the aluminum wheel by using super glue (ERGO 5800; Kisling AG, Wetzikon, Switzerland). In the process of all tests, the same grit was used without dropping off the wheel. 


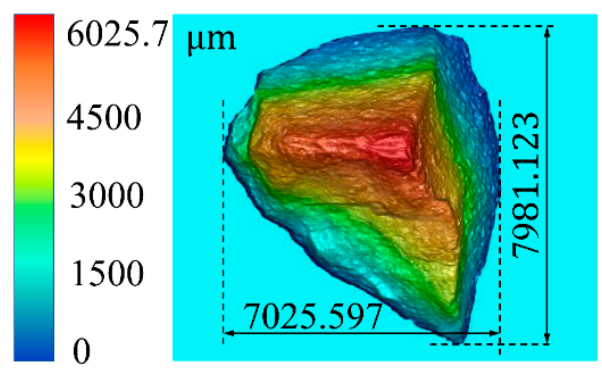

Figure 2. 3D morphology of the grit.

Table 2. The detailed information on the grit.

\begin{tabular}{ccc}
\hline No. & Item & Results \\
\hline 1 & $\mathrm{Mesh}$ & 3 \\
2 & $\mathrm{Al}_{2} \mathrm{O}_{3}$ & $95.0 \%$ \\
3 & $\mathrm{SiO}_{2}$ & $1.0 \%$ \\
4 & $\mathrm{Fe}$ & $0.2 \%$ \\
5 & $\mathrm{Ti}$ & $2.0 \%$ \\
6 & Density & $3.6 \mathrm{~g} / \mathrm{cm}^{3}$ \\
7 & Mohs' hardness & $\geq 8.5$ \\
\hline
\end{tabular}

The materials selected for the test were medium-density fiberboard (MDF) and Korean Pine (Pinus koraiensis Sieb.et Zucc). The MDF was mainly made from Pinus branches using phenolic resin and the Korean Pine was sapwood about 30 years of age. Totally, 12 workpieces (4 for MDF, 8 for Korean Pine) were cut into the size of $130 \mathrm{~mm}$ (long) $\times 30 \mathrm{~mm}$ (wide) $\times 30 \mathrm{~mm}$ (thick). Densities of the workpieces were $0.78 \pm 0.02 \mathrm{~g} / \mathrm{cm}^{3}$ for MDF and $0.33 \pm 0.04 \mathrm{~g} / \mathrm{cm}^{3}$ for Korean Pine. All Korean Pine workpieces were dried in the electrical blast drying box (GZX-9070MBE; Shanghai Boxun Medical Biological Instrument Corp., Shanghai, China) before the experiments started to ensure final moisture content of $8 \% \pm 2 \%$. To precisely examine the microscopic morphology of scratches, the workpieces were levelled with an 80 grit aluminum oxide abrasive belt and then finish-sanded with 100 and 150 grit aluminum oxide abrasive belts using a wide belt-sander (SANDTEQ W-200, HOMAG, Schopfloch, Germany). An area measuring $24 \times 18 \mathrm{~mm}^{2}$ was scanned by 3D Profiler (KEYENCE VR-3200; KEYENCE, Osaka, Japan) and 4 different areas in each workpiece were scanned to obtain the surface roughness $R_{\mathrm{a}}$ of $2.4 \pm 0.3 \mu \mathrm{m}$ and $6.5 \pm 0.7 \mu \mathrm{m}$ for MDF and Korean Pine respectively.

\subsection{The Scratch Direction aAnd Scratch Profile Measurement}

MDF is generally made from different types of wood-based furnish such as pulp chips, planer shavings, plywood trims and sawdust. High mechanical strength and good water resistance are produced after the urea-formaldehyde (UF) or phenol-formaldehyde (PF) application and hot pressing [22]. The irregular spreading fibres and adhesive make it nearly isotropic. Korean Pine, as a kind of softwood, consists of axial tracheid cells, ray parenchyma and resin canals, with tracheids as the main component, making $90 \%-95 \%$ of the wood volume. These component cells vary widely in size [23,24]. In comparison with MDF, the characteristics of Korean Pine vary from each direction mainly because of the biological cell configuration and anatomy. Since material anisotropy exerts an important effect on the surface property, this study chose two directions ( $\lambda$ refers to the angle between the grit movement direction and wood grain direction) in scratching Korean Pine, as illustrated in Figure 3.

The scratch profiles on the workpiece were measured by 3D Profiler (KEYENCE VR-3200; KEYENCE, Osaka, Japan), with the measuring resolution of $0.5 \mu \mathrm{m}$ on the $Z$ axis. Each scratch was scanned after successive scratches were created on a workpiece surface as soon as possible to avoid the effect of air humidity variation. Figure 4a shows a typical 3D morphology of scratches, from which the characteristics of each individual scratch can be clearly seen. To further investigate 
the surface creation of MDF and Korean Pine, 2D cross-sectional profiles were extracted from the deepest point of scratches, as plotted in Figure $4 b$, where depth of cut, groove area, pile-up area (like swelling ridges created by the ploughing effect), and other related parameters can be measured by using analyzing software (VR Series version 2.2.0.89). Depth of cut means the height from the deepest point to baseline. Owing to the original biological surface roughness, the deepest point was generally in the middle of a scratch but sometimes can diverge from the middle zone. Pile-up ratio is the ratio of pile-up area to groove area of each scratch, which is widely used to measure the proportion of ploughing.

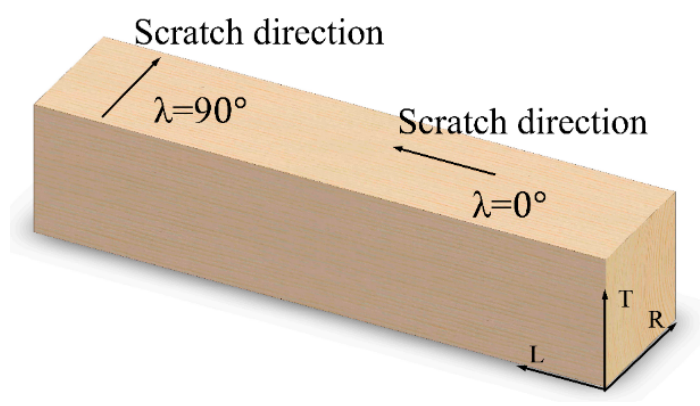

Figure 3. Schematic diagram of scratch direction and wood grain direction.

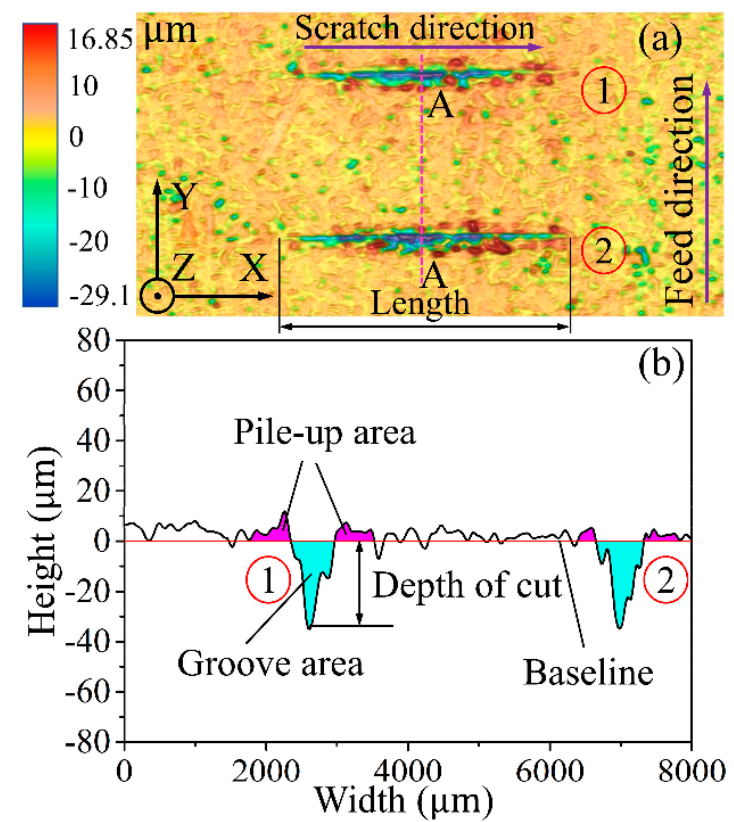

Figure 4. The measurement of scratches cut by single grit: (a) morphology of scratched workpiece surface; (b) cross-sectional profile of scratches.

\subsection{The Grey Relational Grade Analysis (GRGA)}

Since the characteristics of wood materials are complicated and can be affected by moisture content, grain direction, and anatomical structures, grey relational grade analysis (GRGA) was used in this study to figure out the specific influencing weight of depth of cut, groove area, pile-up area, and normal sanding force on pile-up ratio. The grey system theory was proposed by Deng [25]. Grey relational analysis (GRA) is broadly applied in evaluating or judging the performance of a complex project with insufficient information. The grey comprehensive relational grade reflects the similarity between polygonal lines $X_{0}$ and $X_{i}$ geometrically, and it also reflects the proximity of the change rate of $X_{0}$ and $X_{i}$ from the start point. Therefore, it is a good measure to indicate if there is a close relationship between the two sequences.

The processes of grey comprehensive relational grade analysis are as follows: 
- The formation of the refence sequence and the compared sequence.

The reference sequence is marked as $X_{0}=\left(x_{0}(1) x_{0}(2), \cdots, x_{0}(n)\right)$, and the compared sequence is marked as $X_{i}=\left(x_{i}(1) x_{i}(2), \cdots, x_{i}(n)\right)$, where $i=1,2, \cdots, m$ and the $x_{i}(n)$ is the $n$-th element of $X_{i}$.

- The calculation of the grey absolute relational grade.

Let $X_{0}^{0}=\left(x_{0}^{0}(1) x_{0}^{0}(2), \cdots x_{i}^{0}(n)\right)$ and $X_{i}^{0}=\left(x_{i}^{0}(1) x_{i}^{0}(2) \cdots x_{i}^{0}(n)\right)$ are the initialization of $X_{0}$ and $X_{i}$ respectively. Mark:

$$
\begin{array}{r}
\left|S_{i}\right|=\left|\sum_{k=2}^{n-1} x_{i}^{0}(k)+1 / 2 x_{i}^{0}(n)\right| \\
\left|S_{i}-S_{0}\right|=\left|\sum_{k=2}^{n-1}\left(x_{k}^{0}(k)-x_{0}^{0}(k)+1 / 2 x_{i}^{0}(n)-x_{0}^{0}(n)\right)\right|
\end{array}
$$

where $i=1,2, \cdots, m ; k=1,2, \cdots n$. Then, the grey absolute relational grade can be calculated by Equation (3):

$$
\varepsilon_{0 i}=\frac{1+\left|S_{0}\right|+\left|S_{i}\right|}{1+\left|S_{0}\right|+\left|S_{i}\right|+\left|S_{i}-S_{0}\right|}
$$

where $\varepsilon_{0 i}$ is only related to the geometrical shape of $X_{0}$ and $X_{i}$. The bigger $\varepsilon_{0 i}$ value means that the geometrical shapes of $X_{0}$ and $X_{i}$ in the line chart are more similar.

- The calculation of the grey relative relational grade.

Let $X_{i}^{\prime}(k)=\frac{x_{i}(k)}{x_{i}(1)}$, then

$$
\left|S_{i}^{\prime}\right|=\left|\sum_{k=2}^{n-1}{X^{\prime}}_{i}^{0}(k)+1 / 2{x^{\prime}}_{i}^{0}(n)\right|
$$

where $i=1,2, \cdots, m ; k=1,2, \cdots, n$. Then, the grey relative relational grade can be calculated by Equation (5):

$$
R_{0 i}=\frac{1+\left|S_{0}^{\prime}\right|+\left|S_{i}^{\prime}\right|}{1+\left|S_{0}^{\prime}\right|+\left|S_{i}^{\prime}\right|+\left|S_{i}^{\prime}-S_{0}^{\prime}\right|}
$$

The grey relative relational grade characterizes the change rate of the two sequences $X_{0}$ and $X_{i}$ from the start point. The bigger $R_{0 i}$ value means the more proximate the two change rates are.

- The calculation of grey comprehensive relational grade.

$$
\rho_{0 i}=\theta \varepsilon_{0 i}+(1-\theta) R_{0 i}
$$

where $\theta \in[0,1]$. Generally, $\theta=0.5$ is preferable. If more concern is taken into the proximity of broken lines geometry, a bigger $\theta$ can be selected. If more concern is taken into the changing rate, a smaller $\theta$ can be chosen.

\section{Results and Discussion}

\subsection{The Plastic Material Deformation of Scratch Cut by Single Grit}

Figure 5 shows the cross-sectional profiles of the scratched surface and original surface of MDF and Korean Pine workpiece. It is found that the "pile-up" was more obvious in scratching MDF. When scratching Korean Pine $\left(\lambda=0^{\circ}\right)$, there was minute even zero, pile-up occurred on two sides of the groove. Moreover, it is noted that there was a significant difference in the shape of grooves. The groove shape of MDF scratches presented serrated edges mostly. However, the groove shape of Korean Pine $\left(\lambda=0^{\circ}\right)$ scratches was relatively smooth. 

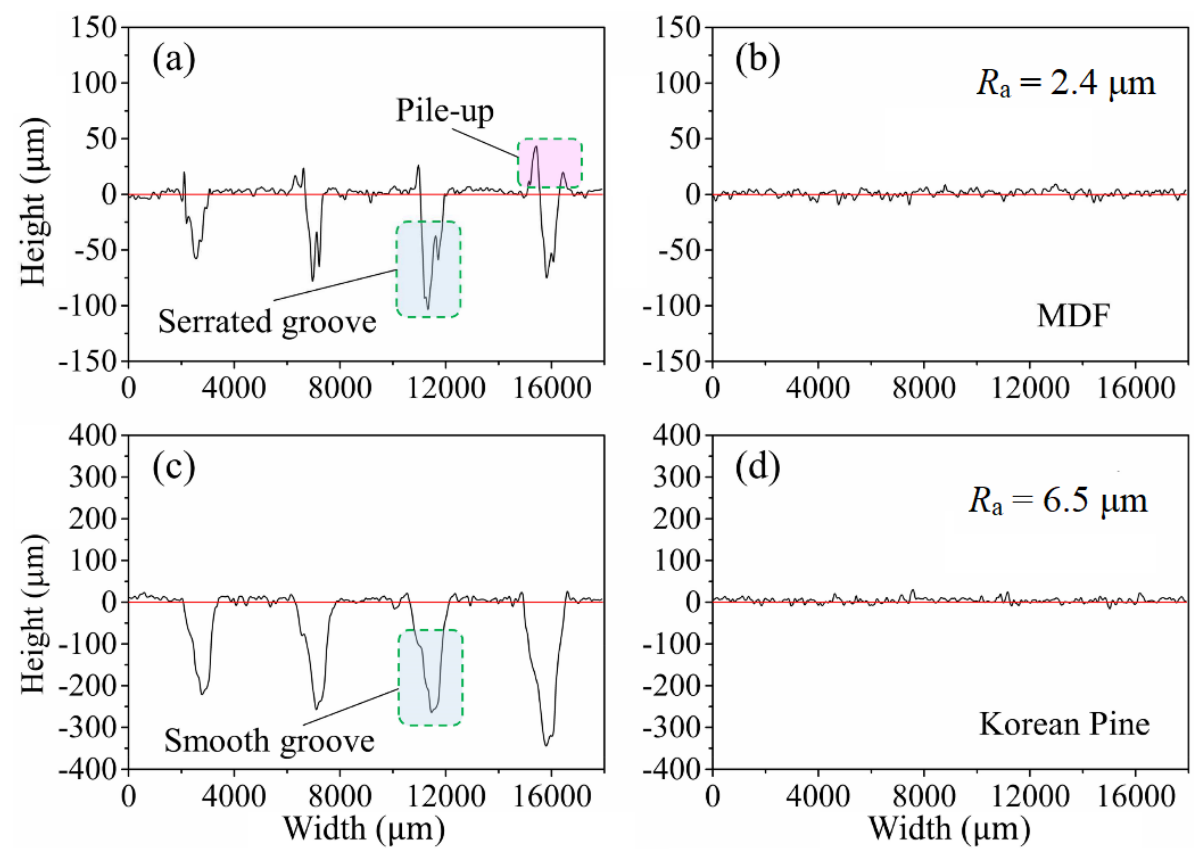

Figure 5. The cross-sectional profiles of scratched surface and original surface: (a) the scratched surface of MDF; (b) the original surface of MDF; (c) the scratched surface of Korean Pine $\left(\lambda=0^{\circ}\right)$; (d) the original surface of Korean Pine.

Since wood is an anisotropic and porous material, and its pore structure affects its behavior more than any other characteristics [23,26], wood grain direction and unevenly distributed porosity (the amount of void volume) were considered to analyze the difference on plastic material deformation between scratching MDF and Korean Pine $\left(\lambda=0^{\circ}\right)$. When scratching Korean Pine $\left(\lambda=0^{\circ}\right)$, the scratch direction is parallel to the wood grain direction. Hence, with the grit movement along the grain direction, the anatomical cavities (axial tracheid cells, resin canals and ray parenchyma cells) are compressed in a direction perpendicular to wood grain direction. The elastic deformation will recover due to the elastic spring back effect after the grit passes. However, the material plastic deformation around the cutting-edge is mostly absorbed by the compressed cavities, which causes tiny even no pile-up, as illustrated in Figure 6a. Knowledge of the pore structure is directly related to the density, and wood density values are significantly low with the highest amount of porosity and the lowest amount of cell wall material [26,27]. In the process of making MDF, the natural structure of wood fibres is destroyed and many shorter fibres are mixed with adhesives in irregular distribution. In addition, the average density of MDF is about twice greater than Korean Pine, which means the porosity of Korea Pine is greater than that of MDF. Therefore, the capability of absorbing deformation for Korean Pine is better than MDF, which partially leads to more pile-up on bilateral sides of the groove in the case of scratching MDF, as shown in Figure $6 b$. The difference of groove shape may also be attributed to the absorbing effect.

The tiny "pile-up" occurred at bilateral sides of scratch (Korean Pine, $\lambda=0^{\circ}$ ) can be partly explained by the anatomical cavities absorbing effect. In addition, "fibres" are thin walled and are easily perforated and shredded during sanding, resulting in the formation of cell walls that are loosely bonded to the underlying wood surface, which was called "grain raising" especially in low-density wood species [5]. Figure 7a,b shows the microscopic images presented by Ultra-Depth 3D Microscope (KEYENCE VHX-6000, KEYENCE, Osaka, Japan) of scratched surface of MDF and Korean Pine $\left(\lambda=0^{\circ}\right)$ workpiece, from which it can be inferred that the tiny "pile up" of Korean Pine scratched surface $\left(\lambda=0^{\circ}\right)$ is more like "grain raising". Figure 7c shows the diagram of force analysis of grit-workpiece interaction, along the arch trajectory path, grit moves with negative rake angle until it reaches the deepest point and the cutting-edge of actual grit has a certain curvature radius. So, the sub-surface 
layer is compressed and densified mostly. When the plastic deformation exceeds the maximum capability of anatomical cavities absorption, there might be pile-up caused by the ploughing effect, which likes swelling ridges above the scratched surface. And, the shredded fibre structure accumulated in front of the rake face is removed if the $F_{n}$ (the horizontal component of $F$ ) is big enough at the grit exit stage.

(a)

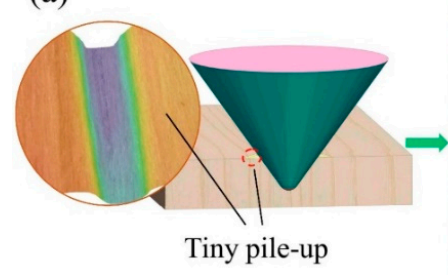

(b)

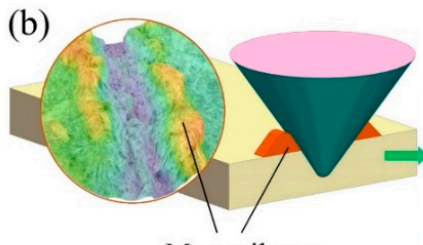

More pile-up
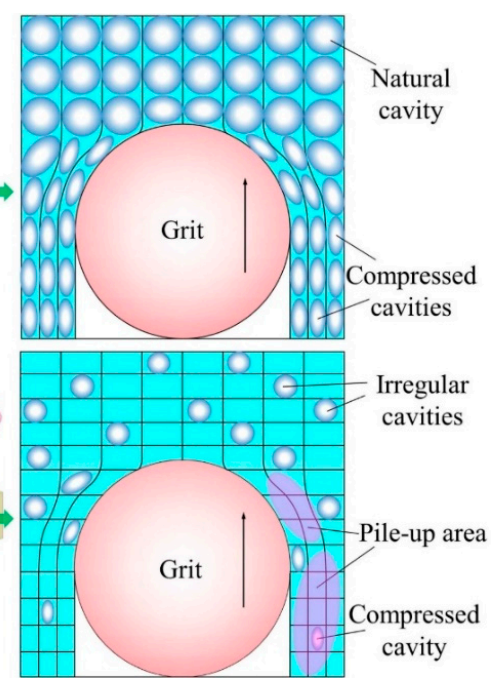

Figure 6. Schematic of the anatomical cavities absorbing effect (a) when scratching Korean Pine $\left(\lambda=0^{\circ}\right)$ and (b) when scratching MDF.

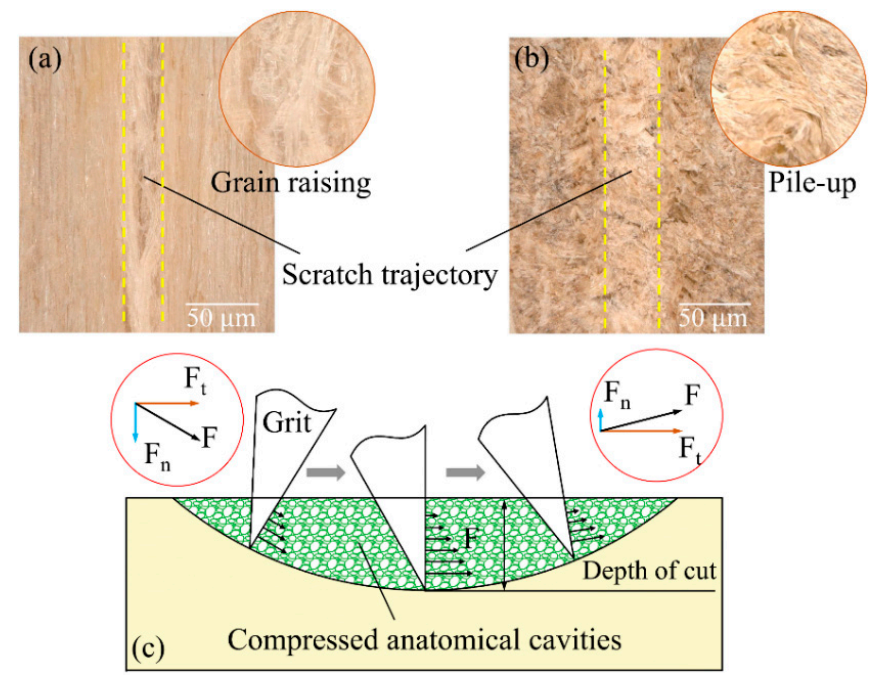

Figure 7. Analysis of plastic material deformation and chip formation when scratching Korean Pine $\left(\lambda=0^{\circ}\right)$ and MDF: (a) Ultra-Depth 3D Microscopic images of Korean Pine scratched surface; (b) Ultra-Depth 3D Microscopic images of MDF scratched surface; (c) the diagram of force analysis of workpiece within the arch trajectory path.

As reported previously, the roughness average $\left(R_{\mathrm{a}}\right)$ was significantly higher in the direction perpendicular to the movement of the abrasive grains than along the grain [28]. Miao and Li found that the surface of Manchurian ash sanded in longitudinal direction seems to be the smoothest, while the surface of Birch sanded in transverse direction appears to have more wood wools [29]. From the surface morphology and cross-sectional profiles of scratching Korean Pine $\left(\lambda=90^{\circ}\right)$, it is observed that groups of wood grain were not cleanly severed by scratching and stood up above bilateral sides of scratch (Figure 8a). In addition, the cross-sectional profiles of cracked wood materials were highly irregular, as the pink-colored area shown in Figure 8b. At the initial stage, the cracked wood grain 
was not obvious with low cutting depth. As the grit moved into the workpiece, more materials cracking occurred, especially around the deepest point of the scratch. Given this, the cracked grain occurred when scratching Korean Pine $\left(\lambda=90^{\circ}\right)$ is more like a great amount of fuzziness rather than plastic pile-up [4]. It indicates that sanding direction exerts great influence on the surface morphology compared with the situation when $\lambda=0^{\circ}$.

To analyze the material removal and surface creation of scratching Korean Pine $\left(\lambda=90^{\circ}\right)$, it is necessary to figure out the form of grit-workpiece interaction. In the case of $\lambda=90^{\circ}$, the rake face of the grit is strongly inclined to the workpiece surface when cutting depth is small at the initial stage [16]. At this time, the interaction between the grit cutting-edge and wood surface is point-contact or line-contact, and the contact length $(W)$ is about zero (Figure $8 \mathrm{c}$ ), where wood grain might be cut off but the fractured grain is hard to be removed in chips. Thus, the workpiece material is mostly crushed to two sides of the scratch. Cell crushing is caused by normal forces that outweighed the ultimate rupture strength of wood tissues [30]. The layer of superficial damaged tissues prevents the penetration of coatings or glues into the wood [31]. Moreover, crushed tissues at the surface and sub-surface might behave as a mechanical weak boundary layer in coating interfaces or gluelines [32,33]. As the grit moves forward, the interaction converts into face-contact, and the $W$ becomes larger. In this case, wood grain can be cut off by side cutting-edges and removed in chips flow in front of the rake face when the shearing stress reaches the fracture strength. The fibre structure was transversely severed by side cutting-edges and caused much fuzzy grain standing up beside the scratch, which might account for the hugely irregular height profile (Figure 8b).

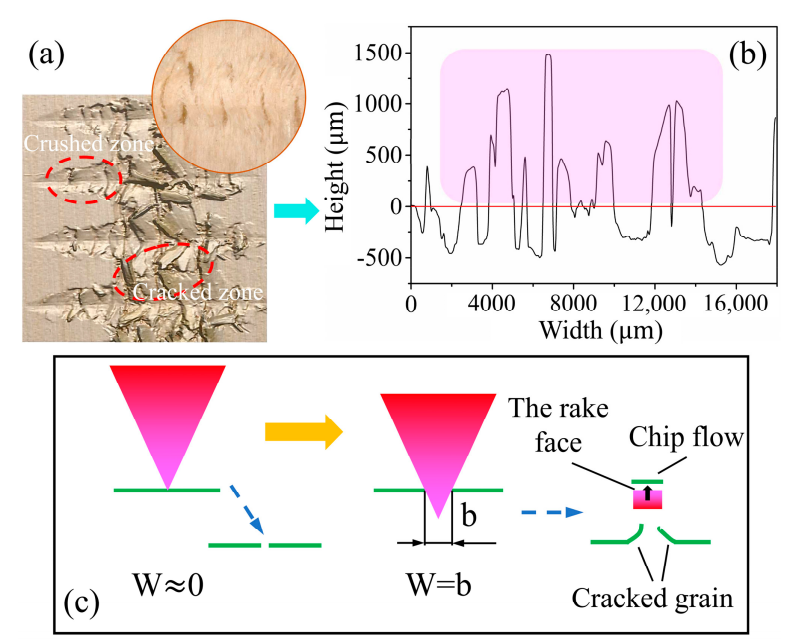

Figure 8. Analysis of plastic material deformation and chip formation when scratching Korean Pine $\left(\lambda=90^{\circ}\right)$ : (a) 3D morphology of Korean Pine scratched surface; (b) cross-sectional profiles of scratched surface; (c) the interaction form between grit cutting-edges and wood grain.

To further investigate the plastic material deformation, it was assumed that both the grain raising and cracked grain at the bilateral sides of scratches were considered as plastic pile-up. Then the effects of groove area and depth of cut on pile-up ratio when scratching MDF and Korean Pine are shown in Figure 9. When looking at the situation of scratching Korean Pine $\left(\lambda=0^{\circ}\right)$, the pile-up ratio of both groove area and depth of cut were concentrated in a pink-colored belt with a range from 0 to 0.05 . Through the case of scratching Korean Pine $\left(\lambda=90^{\circ}\right)$, the pile-up ratio of both groove area and depth of cut were concentrated in a pink-colored belt with a range from 0 to 0.1 , and it can be noted that the maximum pile-up ratio reached nearly 0.6 . In these two circumstances, the ratios varied within a small range and showed no obvious or underlying trend with the variation of groove area and depth of cut. Actually, pile-up ratio is gradually decreasing while scratch depth is increasing with sharp cutting-edge grit [17]. Therefore, the assumption was not correct and the mechanism proposed above was confirmed from one aspect. When scratching MDF, the pile-up ratio presented to be scattered 
highly. And the polynomial fitting shows a decreasing tendency of pile-up ratio when the depth of cut and groove area increase. That means a greater proportion of cutting occurs with the increase of grit penetration depth.
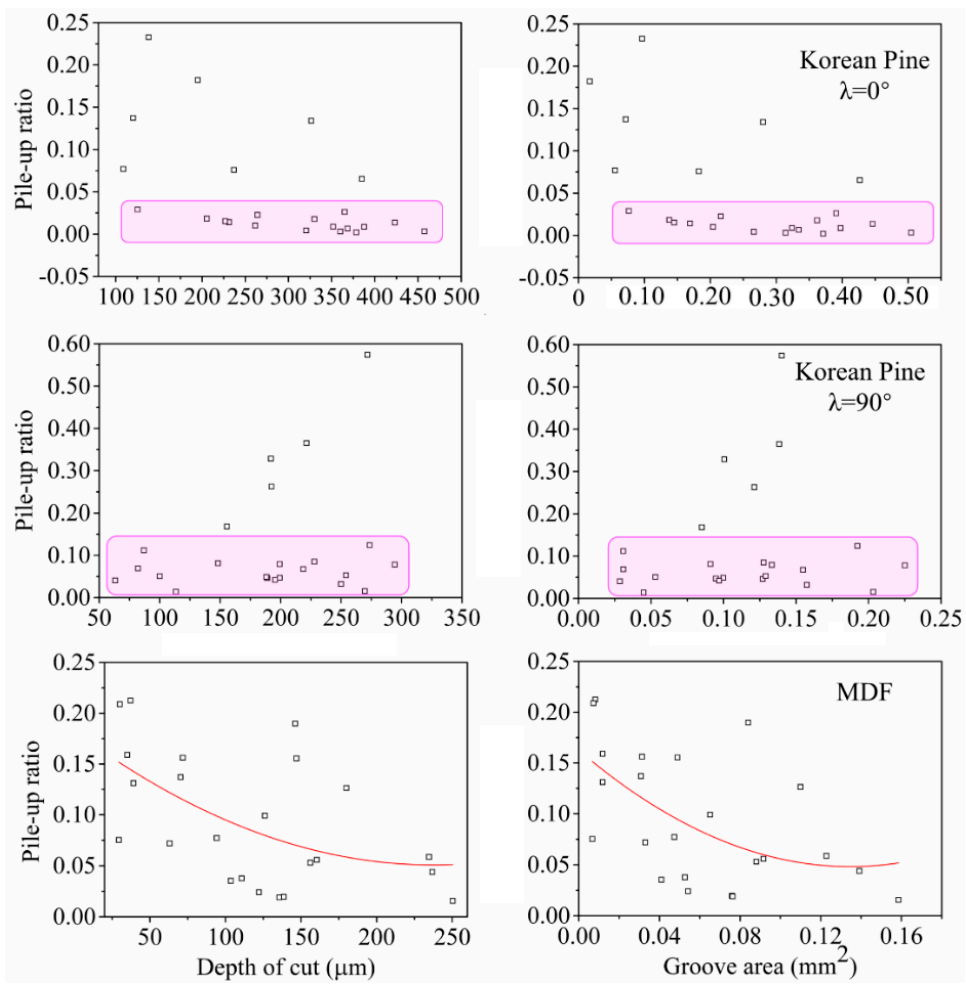

Figure 9. The effects of depth of cut and groove area on pile-up ratio.

To figure out the specific influencing weight of depth of cut, groove area, pile-up area and normal sanding force on pile-up ratio when scratching MDF, Grey relational grade analysis (GRGA) was used. In Equation (6), 0.2 was set as the value of $\theta$ for the dimensions of experimental statistics are different and the statistics vary a lot. Then the pile-up ratio was set as the reference sequence $X_{0}$; the depth of cut, groove area, pile-up area and normal sanding force were set as the compared sequence $X_{1}, X_{2}, X_{3}$ and $X_{4}$ respectively. According to the results listed in Table 3, the four grey comprehensive relational grades are greater than 0.5 , which indicates that they are closely related to pile-up ratio. Specifically, the normal sanding force exerts the greatest influence on the pile-up ratio. This is because normal sanding force directly reflects the density (porosity), the other indices, however, are the indirect results after material deformation and removal.

Table 3. The results of GRGA analysis on pile-up ratio.

\begin{tabular}{ccc}
\hline Grey Comprehensive Relational Grade & Value & Rank \\
\hline$\rho_{01}$ & 0.5680 & 3 \\
$\rho_{02}$ & 0.5230 & 4 \\
$\rho_{03}$ & 0.5962 & 2 \\
$\rho_{04}$ & 0.7504 & 1 \\
\hline
\end{tabular}

In summary, plastic deformation did not necessarily transform into pile-up when scratching Korean Pine. Most of the plastic deformation was absorbed by the anatomical cavities, especially in scratching Korean Pine longitudinally. And that is a marked difference from other engineered materials in sanding or grinding operations. In the case of scratching Korean Pine transversely, much cracked grain like fuzziness occurred owing to the shredding effect of side cutting-edges, and caused bad surface quality. Since early wood and late wood show diverse densities, there might be difference on 
material deformation and surface quality, especially in longitudinal direction. That difference was not taken into account for the scratches with gradual increased cutting depths generated in early wood or late wood randomly in this study. There is more pile-up on two sides of MDF scratch partly because MDF is a kind of densified and incompletely homogeneous material and the porosity is not significant. So, it can be inferred that the material porosity and wood grain direction are two key factors in the wood sanding processes.

\subsection{The Elastic Spring Back Effect During Single Grit Grinding}

Rubbing occurs at the initial stage of grit-workpiece interaction at a very small region, and only elastic deformation is included [12]. Since rubbing is not easily observed due to the elastic spring back effect and the three stages (rubbing, ploughing, cutting) along a scratch vary in proportion and can even occur simultaneously [34], only a few experimental researches on rubbing can be found in grinding metal, alloy or other engineered materials.

Wood is a kind of bio-based polymeric material, which can be regarded as elastic material when it is under small stress during a short period of time. Therefore, to investigate the surface creation mechanism thoroughly in scratching MDF and Korean Pine, the rubbing stage is necessary to be studied. In order to find out the elastic spring back effect during the scratching tests, a new method was developed by precisely matching the sanding force and the surface morphology. Specifically, the actual length $\left(L^{\prime}\right)$ of the scratch can be measured by the analyzing software of the 3D profiler, and the grit entrance time $\left(t_{1}\right)$ and exit time $\left(t_{2}\right)$ of grit-workpiece interaction could be distinguished from the sanding force curve, as shown in Figure 10. Since the interaction time is very short with several microseconds and the penetration depth is relatively small, the velocity of the cutting-edge can be regarded as equal to the instant cutting speed $v_{\mathcal{C}}$, which can be calculated as:

$$
v_{\mathrm{c}}=\frac{\pi D n}{60}
$$

Then, the theoretical length $(L)$ of the scratch can be calculated as:

$$
L=v_{\mathrm{c}} \times \Delta t
$$

where $\Delta t=t_{1}-t_{2}$.

During the arch trajectory, friction forces with the material must also be considered to see if the velocity decay is heavy. Here, the scratch of MDF in Figure 11 was taken as an example. The average tangential sanding force of this scratch is about $12 \mathrm{~N}$, and the contact arch length was about $0.01 \mathrm{~m}$, so the work of friction forces $\Delta E$ was approximately $0.12 \mathrm{~J}$. If the friction energy loss was provided completely by the rotational kinetic energy of the wheel, then the velocity variation can be calculated as:

$$
\frac{1}{2} J\left(\Delta v_{\mathrm{c}} / R\right)^{2}=\Delta E
$$

where $J$ is the moment of inertia of the wheel, and $R$ is the wheel radius. So, the velocity decay is about $1.1 \mathrm{~m} / \mathrm{s}$. Moreover, the electrical spindle provided about $1.35 \mathrm{~J}$ during the $\Delta t(0.9 \mathrm{~ms})$. And that means the method proposed above is appropriate for this outstanding question.

The results are listed in Table 4. Compared with the actual length, the theoretical length was larger both in scratching MDF and Korean Pine $\left(\lambda=0^{\circ}\right.$ and $\left.\lambda=90^{\circ}\right)$, which strongly indicates that the material elastic deformation recovered after the grit passes. 

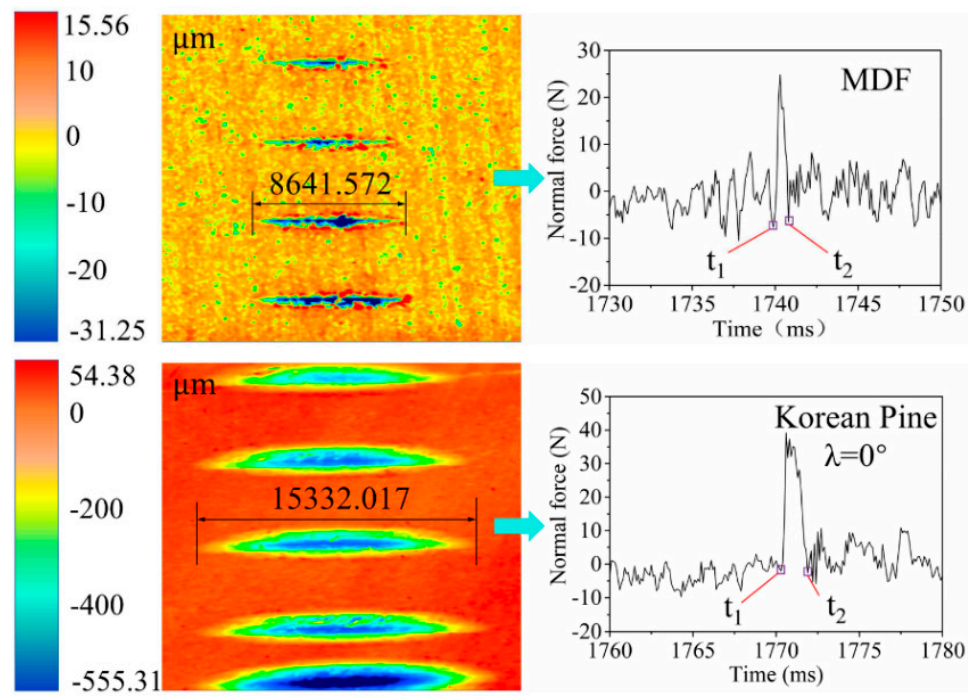

Figure 10. The accurate match of surface morphology and sanding force during a single scratch.

Table 4. Comparison of the theoretical length $(L)$ and measured length $\left(L^{\prime}\right)$ of the scratch.

\begin{tabular}{cccc}
\hline Comparison & $\boldsymbol{L}(\boldsymbol{\mu m})$ & $\boldsymbol{L}^{\prime}(\boldsymbol{\mu m})$ & $\Delta \boldsymbol{L}=\boldsymbol{L}-\boldsymbol{L}^{\prime}(\boldsymbol{\mu m})$ \\
\hline MDF & 10489.5 & 8641.6 & 1847.9 \\
Korean Pine $\left(\lambda=0^{\circ}\right)$ & 18648.0 & 15332.0 & 3316.0 \\
Korean Pine $\left(\lambda=90^{\circ}\right)$ & 16317.0 & 12242.1 & 4074.9 \\
\hline
\end{tabular}

In order to illustrate the accurate and comprehensive information on scratching Korean Pine $\left(\lambda=90^{\circ}\right)$, the normal force voltage signal curve was plotted in Figure 11a. The elastic spring back effect seems to be more obvious at the exit side and a little longer path at the end of the scratch was observed, which is different from the case of $\lambda=0^{\circ}$. That is mainly because of the scratch direction. While the grit was leaving the workpiece from the deepest point, the fractured material accumulation in front of the rake face kept compressing the material around the grit cutting-edges, which caused elastic and plastic deformation simultaneously. In addition, the grit-workpiece contact length was decreasing due to the decreasing cutting depth, and the transverse fibre structure was hard to be severed when the cutting depth was relatively small. Therefore, the compressive action on the surface layer mainly led to elastic deformation and the elastic deformation recovered after the grit left the workpiece, as demonstrated in Figure 11b, which can perfectly account for the more obvious and stronger elastic spring back effect at the exit side of the scratch.

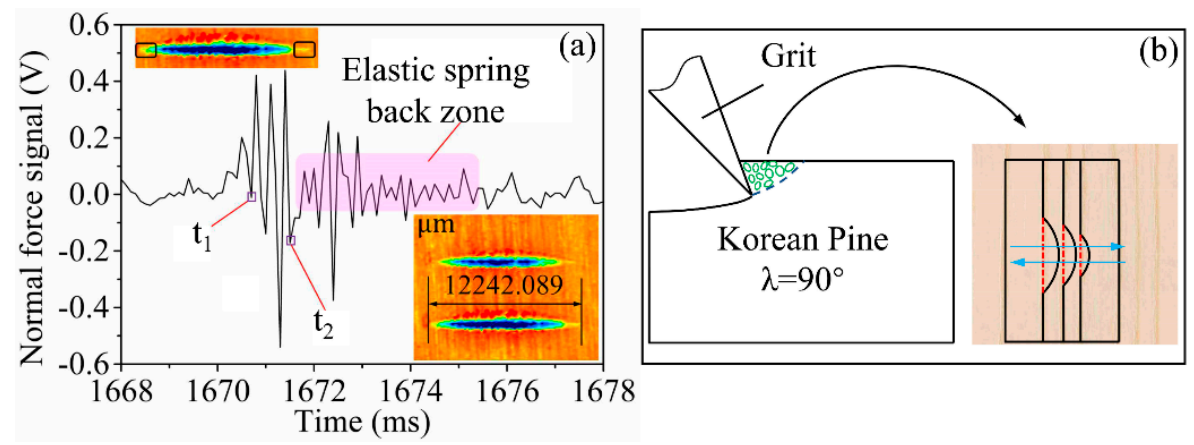

Figure 11. The analysis of elastic spring back effect when scratching Korean Pine $\left(\lambda=90^{\circ}\right)$ : (a) the exact match of sanding force and scratch morphology; (b) schematic of the elastic spring back effect when the grit was about to leave the workpiece. 


\section{Conclusions}

The material removal and surface creation process of sanding MDF and Korean Pine was studied with single grit scratching tests. It is found that there are some differences in the material deformation during scratching Korean Pine and MDF. A mechanism was suggested to account for the differences. This mechanism helps to explain why tiny even no pile-up occurs during scratching Korean Pine, especially in the longitudinal direction. It can be inferred that the material porosity and wood grain direction are two key factors in the wood sanding processes. As for MDF, there is a decreasing tendency of pile-up ratio when the depth of cut and groove area increase, and the normal sanding force exerts the greatest influence on pile-up ratio. At the rubbing stage, a new method to confirm the elastic spring back effect was developed. And it is verified that elastic deformation both in MDF and Korean Pine scratching did exist through mathematical calculations. The material removal and surface creation are fertile areas for wood sanding research, and the approaches used here could provide insights to investigate other wood species and wood composites to improve sanding efficiency and surface quality eventually. Further research will focus on the effects of grit geometry and wood species with different densities and the effects of early wood and late wood on material removal and surface creation during the sanding process.

Author Contributions: Data Curation, J.Z.; Formal Analysis, J.Z.; Funding Acquisition, H.L.; Investigation, J.Y. and F.C.; Methodology, J.Z. and B.L.; Project Administration, L.L.; Software, J.Y. and F.C.; Supervision, B.L., H.L. and L.L.; Writing-Original Draft Preparation, J.Z.; Writing-Review \& Editing, B.L., H.L. and L.L.

Funding: This research was funded by the Fundamental Funds for the Central Universities (No. 2017JC11).

Acknowledgments: The authors are grateful for the support of MOE Key Laboratory of Wooden Material Science and Application, Beijing Key Laboratory of Wood Science and Engineering at Beijing Forestry University.

Conflicts of Interest: The authors confirm that no conflict of interest exists in this article.

\section{References}

1. Ratnasingam, J.; Reid, H.; Perkins, M. The abrasive grinding of rubberwood (Hevea brasiliensis): An industrial perspective. Eur. J. Wood Prod. 2002, 60, 191-196. [CrossRef]

2. Bao, X.; Ying, J.H.; Cheng, F.; Zhang, J.; Luo, B.; Li, L.; Liu, H.G. Research on neural network model of surface roughness in belt grinding process for Pinus koraiensis. Measurement 2018, 115, 11-18. [CrossRef]

3. Sulaiman, O.; Hashim, R.; Subari, K.; Liang, C.K. Effect of grinding on surface roughness of rubberwood. J. Mater. Process. Technol. 2009, 209, 3949-3955. [CrossRef]

4. Stewart, H.A. Some surfacing defects and problems related to wood moisture content. Wood Fiber 1980, 12, 175-182.

5. Evans, P.H.; Cullis, I.; Kim, J.; Leung, H.L.; Hazneza, S.; Heady, R.D. Microstructure and mechanism of grain raising in Wood. Coatings 2017, 7, 135. [CrossRef]

6. Koehler, A. Some observations on raised grain. Trans. Am. Soc. Mech. Eng. 1932, 54, 27-30.

7. Taylor, J.B.; Carrano, A.L.; Lemaster, R.L. Quantification of process parameters in a wood sanding operation. For. Prod. J. 1999, 49, 41-46.

8. Luo, B.; Li, L.; Liu, H.; Xu, M.; Xing, F. Analysis of sanding parameters, sanding force, normal force, power consumption, and surface roughness in sanding wood-based panels. Bioresources 2014, 9, 7494-7503. [CrossRef]

9. Xu, M.; Li, L.; Wang, M.; Luo, B. Effects of surface roughness and wood grain on the friction coefficient of wooden materials for wood-wood frictional pair. Tribol. Trans. 2014, 57, 871-878. [CrossRef]

10. Cool, J.; Hernández, R.E. Improving the sanding process of black spruce wood for surface quality and water-based coating adhesion. For. Prod. J. 2011, 61, 372-380. [CrossRef]

11. Sun, Y.; Li, L. Effect on bonding strength of surface roughness of sanding wood. Wood Process. Mach. 2010, 21, 41-43. (In Chinese).

12. Hahn, R.S. On the Mechanics of the grinding process under plunge cut conditions. J. Eng. Ind. 1966, 88, 72-80. [CrossRef] 
13. Klocke, F. Principles of cutting edge engagement. In Manufacturing Process 2: Grinding, Honing, Lapping; Kuchle, A., Ed.; Springer: Berlin/Heidelberg, Germany, 2009; pp. 3-16.

14. Chen, X.; Öpöz, T.T. Simulation of grinding surface creation-A single grit approach. Adv. Mater. Res. 2010, 126-128, 23-28. [CrossRef]

15. Anderson, D.; Warkentin, A.; Bauer, R. Comparison of spherical and truncated cone geometries for single abrasive-grain cutting. J. Mater. Process. Technol. 2012, 212, 1946-1953. [CrossRef]

16. Rasim, M.; Mattfeld, P.; Klocke, F. Analysis of the grain shape influence on the chip formation in grinding. J. Mater. Process. Technol. 2015, 226, 60-68. [CrossRef]

17. Öpöz, T.T.; Chen, X. Experimental investigation of material removal mechanism in single grit grinding. Int. J. Mach. Tools Manuf. 2012, 63, 32-40. [CrossRef]

18. Ohtani, T.; Tanaka, C.; Usuki, H. Comparison of the heterogeneity of asperities in wood and aluminum grinding surfaces. Precis. Eng. 2004, 28, 58-64. [CrossRef]

19. Gibson, L.J.; Ashby, M.F. Cellular Solids: Structure and Properties; Cambridge University Press: Cambridge, UK, 1988; p. 387.

20. Lee, P.H.; Nam, J.S.; Li, C.; Sang, W.L. An experimental study on micro-grinding process with nanofluid minimum quantity lubrication (MQL). Int. J. Precis. Eng. Manuf. 2012, 13, 331-338. [CrossRef]

21. Wang, S.; Li, C.; Zhang, X.; Zhou, D.; Zhang, D.; Zhang, Q. Modeling and simulation of the single grain grinding process of the nano-particle jet flow of minimal quantity lubrication. Open Mater. Sci. J. 2014, 8, 55-62. [CrossRef]

22. Widsten, P. Oxidative Activation of Wood Fibers for The Manufacture of Medium-Density Fiberboard (MDF). Ph.D. Thesis, Helsinki University of Technology, Espoo, Finland, November 2002.

23. Almeida, G.; Hernádez, R. Influence of the pore structure of wood on moisture desorption at high relative humidities. Wood Mater. Sci. Eng. 2007, 2, 33-44. [CrossRef]

24. Andersson, S. A study of the Nanostructure of the Cell Wall of the Tracheids of Conifer Xylem by X-ray Scattering. Ph.D. Thesis, University of Helsinki, Helsinki, Finland, January 2007.

25. Deng, J.L. Introduction to Grey system theory. J. Grey Syst. 1989, 1, 1-24.

26. Ding, W.D.; Koubaa, A.; Chaala, A.; Belem, T.; Krause, C. Relationship between wood porosity, wood density and methyl methacrylate impregnation rate. Wood Mater. Sci. Eng. 2008, 3, 62-70. [CrossRef]

27. Usta, I. Comparative study of wood density by specific amount of void volume (porosity). Turk. J. Agric. For. 2003, 27, 1-6.

28. De Moura, L.F.; Hernández, R.E. Effects of abrasive mineral, grit size and feed speed on the quality of sanded surfaces of sugar maple wood. Wood Sci. Technol. 2006, 40, 517-530. [CrossRef]

29. Tian, M.; Li, L. Study on influencing factors of sanding efficiency of abrasive belts in wood materials sanding. Wood Res. 2014, 59, 835-842.

30. Stewart, H.A.; Crist, J.B. SEM examination of subsurface damage of wood after abrasive and knife planing. Wood Sci. 1982, 14, 106-109.

31. De Meijer, M.; Thurich, K.; Militz, H. Comparative study on penetration characteristics of modern wood coatings. Wood Sci. Technol. 1998, 32, 347-365. [CrossRef]

32. Hernández, R.E.; de Moura, L.F. Effects of knife jointing and wear on the planed surface quality of northern red oak wood. Wood Fiber Sci. 2002, 34, 540-552.

33. De Moura, L.F.; Hernández, R.E. Evaluation of varnish coating performance for two surfacing methods on sugar maple wood. Wood Fiber Sci. 2005, 37, 355-366.

34. Öpöz, T.T.; Chen, X. Experimental study on single grit grinding of Inconel 718. Proc. Inst. Mech. Eng. Part B J. Eng. Manuf. 2014, 229, 713-726. [CrossRef]

(C) 2018 by the authors. Licensee MDPI, Basel, Switzerland. This article is an open access article distributed under the terms and conditions of the Creative Commons Attribution (CC BY) license (http:/ / creativecommons.org/licenses/by/4.0/). 